\title{
Mathematical Model of Direct Contact Membrane Distillation for Orange Juice Concentration
}

\author{
Mrunal B. Morey, Vipul N. Gandhi, and Samir K. Deshmukh
}

\begin{abstract}
Membrane distillation (MD) is receiving recent attention as a technique to efficiently concentrate aqueous solution. It has potential benefits of low temperature and pressure operation with high degrees of separation. Orange Juice has to be concentrated by direct contact membrane distillation. The Dusty Gas Model describes membrane distillation through a porous membrane. Analysis of an applied Dusty Gas Model has identified a possible way to optimise flux by an optimal combination of operating parameter and design factor. A model for a membrane distillation process in a plate-and-frame unit has been developed. It is based on a mass and energy balance equation for hydrodynamic, temperature and concentration boundary layers. The model takes into account energy interdependence between flow in feed and in permeate channels. Amodeltaking into consideration temperature concentration polarization (TCP) predicts temperature and concentration values at the membrane surface. The model consists of an analytical equation and permits simulation or analysis of the influence of various factors to permeate flux.
\end{abstract}

Index Terms-Dusty gas model, orange juice, TPC.

\section{INTRODUCTION}

Membrane distillation (MD) is an emerging technology for separations that are traditionally accomplished by conventional separation processes such as distillation or reverse osmosis. Since its appearance in the late of the 1960s and its development in the early of 1980s with the growth of membrane engineering, MD claims to be a cost effective separation process that can utilize low-grade waste and/or alternative energy sources such as solar and geothermal energy. [1] Membrane distillation (MD) is a hybrid process that uses membranes and operates based on evaporation. Unlike most other membrane processes, MD does not require a mechanical pressure pump and is not limited by the osmotic pressure. [2] In MD, mass is transported by the difference in vapor pressures between feed and permeate. The most common configuration of MD is direct contact membrane distillation (DCMD) in which both heated feed and cold permeate streams are in direct contact with the porous, hydrophobic membrane. The difference in the temperature and composition of solutions in the layers adjoining the

Manuscript received September 4, 2013; revised November 30, 2013. Mathematical Model of Direct Contact Membrane Distillation for Orange Juice Concentration.

M. B. Morey and V. N. Gandhi are with the Jawaharlal Darda Institute of Engineering and Technology, Yavatmal 445001, Maharashtra, India. From Sant Gadge Baba Amravati University (e-mail: mrunal.b.morey@gmail.com mr.vipulg1993@rediffmail.com).

S. K. Deshmukh is with the Chemical Engineering Department, Jawaharlal Darda Institute of Engineering and Technology, Yavatmal 445001, Maharashtra, India (e-mail: samirdesh23@yahoo.com). membrane between the feed and permeate streams creates the vapor pressure driving force for DCMD. On the other hand, the chemical potential resulting from the temperature difference plays an important role in both heat and mass transport. [2]-[6] The vaporization at the hot feed-membrane surface interface produces the vapor, which is then driven across the membrane by various mass transport mechanisms, and condenses at the membrane surface-cold permeate solution interface. The hydrophobicity of the membrane protects against liquid penetration through the membrane. Thus, only vapor or gas phase is allowed to enter the membrane pores. [7] The potential advantages of MD process in comparison to the conventional separation processes rely on the lower operating temperature and hydrostatic pressure. Feed solutions having temperatures much lower than its boiling point under pressures near atmosphere can be used. It must be pointed out that in MD, the membrane itself acts only as a barrier to hold the liquid/vapor interfaces at the entrance of the pores and it is not necessary to be selective as required in other membrane processes such as pervaporation. [8] The concentration of fruit juices provides a reduction of transport, packaging and storage costs. In addition the concentrations are more stable, presenting higher resistance to microbial activity than the original juice in similar conditions. It also enables the compensation of change in quality, quantity and price of fruit juice between harvests. During the concentration process, the water should be removed selectively in order to obtain a product with an appearance and taste as close as possible to the original juice. [9]-[11].

\section{DEVELOPMENT OF MODEL}

In the MD process, the water from a separated solution is transported as a vapor through pores of a hydrophobic membrane. A few assumptions were made to analyze the water flux. The main ones are 1) A porous hydrophobic membrane separates two aqueous liquid phases kept at two different temperatures 2) Both the solutions are in direct contact with the surface of the hydrophobic membrane 3) The vapor-liquid equilibrium exists on both sides of the membrane 4) Evaporation occurs at the warm solution-hydrophobic membrane interface 5) All vapor produced $\mathrm{m}$ the warm cell permeates through the membrane in the form of the gas phase, without condensed water being left in the membrane pores 6) The vapor diffuses through a stagnant air layer within the membrane pores to the cooler interface where it condenses 7) The MD process occurs at atmospheric pressure

The system to be studied consists of a porous hydrophobic membrane, which is held between two symmetric channels. 
Hot water is circulated through one of the channels and cold water through the other one. The hot and cold fluids counter-flow tangentially to the membrane surface in a flat membrane module. The temperature difference through the membrane gives rise to a water vapor pressure difference and, consequently to a water flux, $J$, through the membrane. The heat requirements for water evaporation at the membrane-liquid interface have to be supplied from the hot liquid phase. In the same way, the condensation heat at the other membrane-liquid interface has to be removed to the cold liquid phase. This creates temperature gradients in the liquid films adjoining the membrane. This phenomenon is called temperature polarization along the coordinate perpendicular to the membrane, which will be considered as y coordinate. This means that the temperatures at the limit of the thermal boundary layers $\left(T_{\delta 1}\right.$ and $\left.T_{\delta 2}\right)$ are different from the corresponding values on the membrane surfaces $\left(T_{\mathrm{m} 1}\right.$ and $T_{\mathrm{m} 2}$ ), as shown in Fig. 1. In addition, the flux through the membrane creates temperature gradients along the flow direction (the $x$-coordinate) in both channels. So, the temperature profile shown in Fig. 1 refers to a generic position $x$ along the channel flow.

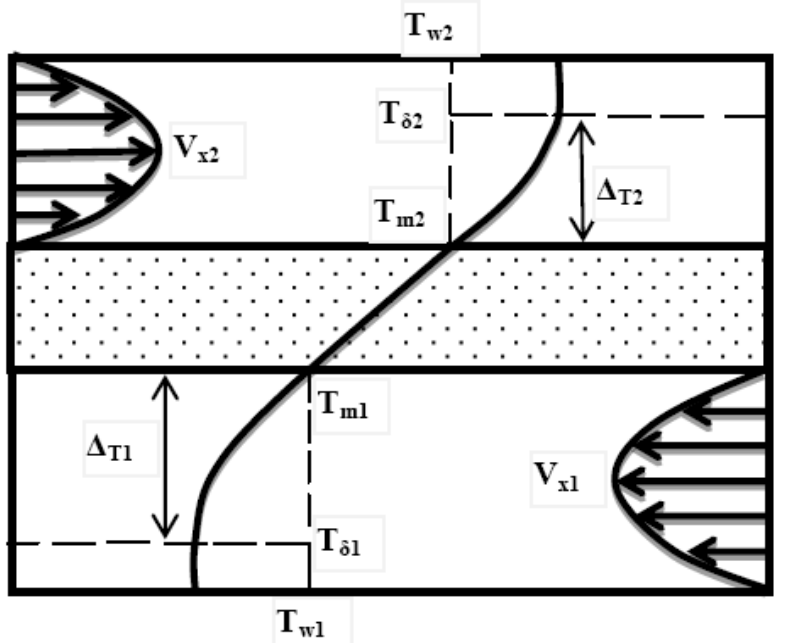

Fig. 1. Temperature and velocity profiles along they-coordinate at a generic $x$-position of the membrane module. The meaning of the different temperatures is indicated.

The overall flux of water vapour for the complete membrane module can be obtained according to

$$
J=(1 / L) \int_{0}^{L} J(x) d x
$$

where $J(x)$ is the local mass flux and $L$ the length of the module channels. The local flux can be calculated by

$$
J(x)=C(x)[p 1(x)-p 2(x)]
$$

where $p_{\mathrm{m} 1}$ and $p_{\mathrm{m} 2}$ are the water vapour pressures corresponding to the temperatures $T_{\mathrm{m} 1}$ and $T_{\mathrm{m} 2}$ on the hot and cold membrane surfaces, respectively. With the assumption of liquid-vapour equilibrium at the pore ends, $p_{\mathrm{m} 1}$ and $p_{\mathrm{m} 2}$ can be evaluated from the Antoine equation:

$$
p i=\exp \left(23.238-\frac{3841}{T m i-45}\right) i=1,2
$$

In Eq. (2), $C$ is the water vapour transfer coefficient of the membrane which depends on membrane structural characteristics (porosity $\varepsilon$, thickness $\delta$, tortuosity $\xi$ ) as well as on operating temperatures and pressures. According to the dusty-gas model for gas transport through porous media, in the system studied the vapour transport through the membrane pores takes place via a combined Knudsen/molecular mechanism as given in electrical analogy given by Fig. 2. In this case $C$ may be written:

$$
C=\frac{\varepsilon}{\chi \delta} \frac{M}{R T}\left(\frac{1}{D_{K}}+\frac{P a}{p D w a}\right)_{\log \text { mean }}^{-1}
$$

where $M$ is the molecular weight of water, $R$ the gas constant, $\bar{T}$ the average temperature along the pores, $p_{a}$ the pressure of the air entrapped in the pores, and $p$ the total pressure inside the pores. This last pressure is considered equal to the static pressure above the liquids in the feed and permeate holding tanks, which in the experiments was the atmospheric pressure. In this way, $p$ is equal to the sum of $p_{\text {a }}$ and the water vapour pressure within the pore. The sub index log mean indicates the logarithmic mean of $\left(1 / D_{K}+p a /\right.$ $p D w a)^{-1}$ in both membrane surfaces. In Eq. (4), $D_{\text {wa }}$ is the diffusion coefficient of water vapour in air, and $D_{K}$ the Knudsen diffusion coefficient of water vapour, which is given by

$$
D k=\frac{2}{3} r\left(\frac{8 R T}{\Pi M}\right)^{1 / 2}
$$

where $r$ is the radius of the membrane pores. The value of $p D_{w a}\left(\mathrm{~Pa} / \mathrm{m}^{2} \mathrm{~s}\right)$ for water-air is given

$$
P, D w a=4.46 T^{2.334} 10^{-6}
$$

So, we can calculate the water flux through the membrane as

$$
J=\frac{1}{L} \int_{0}^{L} C(x)[p 1(x)-p 2(x)] d x
$$

where $C(x)$ is given by Eq. (4), and $\bar{T}$ the average temperature. $\left(T_{\mathrm{m} 1}(x)+T_{\mathrm{m} 2}(x)\right) / 2$

Any theoretical study of gas permeation through microporous structures begins with a comparison of the mean free path of the gas and the mean pore size of the structure as one electrical analogy shown in Fig. 2. If the mean free path of the gas is much less than the pore size, then the dominant flux mechanism is viscous or Poiseuille flow. If the mean free path is much greater than the pore size, then Knudsen diffusion is the dominant mechanism.

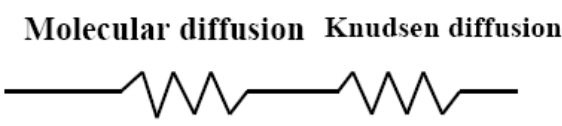

Fig. 2. Electrical analogical circuit for single pore size model: dusty gas model.

\section{RESUlT AND DisCUSSION}

\section{Effect of Temperature Difference}

Fig. 3 and Table I show the results obtained at four constant temperatures of juice in the hot cell $\left(40^{\circ} \mathrm{C}, 50^{\circ} \mathrm{C}\right.$, 
$60^{\circ} \mathrm{C}$ and $\left.70^{\circ} \mathrm{C}\right)$ with constant cold cell temperatures $\left(30^{\circ} \mathrm{C}\right)$. During experiments the feed $(72 \mathrm{l} / \mathrm{hr})$ and permeate velocity $(30 \mathrm{~L} / \mathrm{hr})$ were maintained constant. The flux was calculated based on experimental data using the following equation:

$$
J=\frac{\text { measured permeate flow rate }}{\text { membrane area }}
$$

The fluxes exhibit an exponential dependence on temperature - as w3ould be expected when considering the Antoine equation for vapor pressure of water:

$$
P m i=\exp \left(23.238-\frac{3841}{T m i-45}\right), i=1,2
$$

where $p$ is the vapor pressure of water in $P a$ and $T$ is the temperature in $K$.

The flux increased exponentially with temperature. The temperature difference creates vapor pressure difference and thus the membrane distillation flux rises. This leads to water vapor diffusion through the membrane. At lower temperature difference across the membrane, the transmembrane flux decreases as expected due to lower vapor pressure difference between feed and permeate.

TABLE I: VAPOR PRESSURE VS FLUX

TABLE I: VAPOR PRESSURE VS FLUX
\begin{tabular}{|l|c|c|c|c|c|c|c|}
\hline $\begin{array}{l}T_{f} \\
(\mathrm{~K})\end{array}$ & $T_{p}(\mathrm{~K})$ & $T_{1}(\mathrm{~K})$ & $T_{2}(\mathrm{~K})$ & $P^{\circ}{ }_{1}(\mathrm{~Pa})$ & $P^{\mathrm{o}}{ }_{2}(\mathrm{~Pa})$ & $\Delta P(\mathrm{~Pa})$ & $J \mathrm{Kg} / \mathrm{m}^{2} \mathrm{~h}$ \\
\hline 313 & 303 & 312.10 & 303.81 & 7030.40 & 4438.18 & 2592.22 & 7.2 \\
\hline 323 & 303 & 321.10 & 305.07 & 11475.84 & 4807.82 & 6668.02 & 16.5 \\
\hline 333 & 303 & 330.67 & 306.04 & 17997.71 & 5054.32 & 12943.39 & 23.0 \\
\hline 343 & 303 & 339.96 & 307 & 27391.82 & 5313.46 & 22078.36 & 26.1 \\
\hline
\end{tabular}

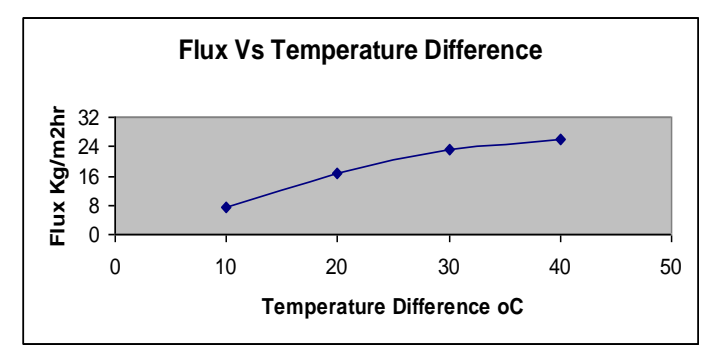

Fig. 3. Effect of temperature difference on transmembrane flux using PTFE membrane (Feed flow rate $72 \mathrm{~L} / \mathrm{hr}$, permeate flow rate $30 \mathrm{~L} / \mathrm{hr}$, permeate temperature $30^{\circ} \mathrm{C}$ and $\left.11.5^{\circ} \mathrm{Brix}\right)$.

\section{Mathematical Models for Calculation of TRANSMEMBRANE FLUX}

The effect of the various parameters on permeate flux has been investigated in the DCMD configuration. The temperature has been varied from 30 to $70^{\circ} \mathrm{C}$ (below the boiling point of the feed solution) and cold side temperature $T_{\mathrm{p}}$ has been varied from $20^{\circ} \mathrm{C}$ to $30^{\circ} \mathrm{C}$ maintaining all other MD parameters constant.

Following parameters and their numerical values are considered constant for calculations:

PTFE membrane parameters:

- Membrane thickness $(\delta)=0.16 \mu \mathrm{m}$.

- $\quad$ Porosity $(\varepsilon)=0.7$,

- Tortuosity $(\xi)=2$,

- Thermal conductivity $(k)=0.29 \mathrm{~W} / \mathrm{mK}$

- Universal gas constant $®=8314 \mathrm{~m}^{3} \mathrm{~Pa} / \mathrm{molK}$

- $\quad$ Radius of membrane pores ${ }^{\circledR}=0.2 \mu \mathrm{m}$
- $\quad$ Molecular weight of water $(\mathrm{M})=18$

\section{Mass Transfer Modeling}

Fluxes and membrane distillation coefficient were used to asses the performance of mass transfer models. The membrane distillation coefficient is defined by:

$$
C=\frac{J}{P_{w}{ }^{f}-P_{w}{ }^{p}}
$$

The calculations were performed by using mass transfer model Equation (4) and shown in Fig. 4. The experimental fluxes $\left(J_{\text {exp }}\right)$ and Membrane distillation Coefficient $\left(C_{\text {exp }}\right)$ are compared to the calculated values. In the calculations, the tortuosity factor $(x)$ for all membrane was presumably equal to 2. Due to complex geometries of most membranes and the uncertainty of their characteristics, it is not practical to use these equations for prior prediction of MDC. Because the mean free path of saturated water vapor under typical DCMD operating conditions is comparable to the typical pore size used in MD membranes, two or three of the three mechanisms mentioned may exist in one membrane so the transmembrane water flux should be described by a combination of mechanisms. Based on Dusty Gas model Lawson et al. developed a Knudsen-molecular transition model given by Eq. 4 (Curve B) fits the experimental data (Curve A) accurately. Other Curve C (Dusty Gas Model), D (Pure Knudsen Diffusion), F (Molecular Diffusion ) and G (Poisullies Flow ) are different model studies from literatures and tabulated in Table II given below.

TABLE II: COMPARISION OF MDC (DUSTY GAS MODEL AND EXPRIMENTATAL)

\begin{tabular}{|c|l|c|c|c|c|}
\hline \multirow{2}{*}{$T_{f} \mathrm{~K}$} & $\Delta P(\mathrm{~Pa})$ & \multicolumn{2}{|c|}{$\mathrm{MDC}, 10^{-6} \mathrm{Kg} / \mathrm{m}^{2}$ sec Pa } & \multicolumn{2}{c|}{ Flux $\mathrm{Kg} / \mathrm{m}^{2} \mathrm{hr}$} \\
\cline { 3 - 6 } & & Measured & Calculated & Measured & Calculated \\
\hline 313 & 2592.22 & 7.71 & 7.59 & 7.2 & 7.08 \\
\hline 323 & 6668.02 & 6.87 & 6.52 & 16.5 & 15.65 \\
\hline 333 & 12943.39 & 4.93 & 5.19 & 23.0 & 24.18 \\
\hline 343 & 22078.36 & 3.28 & 3.52 & 26.1 & 27.97 \\
\hline 353 & 35221.77 & 2.45 & 2.72 & 31.13 & 34.48 \\
\hline
\end{tabular}

MDC Vs Feed Temperature

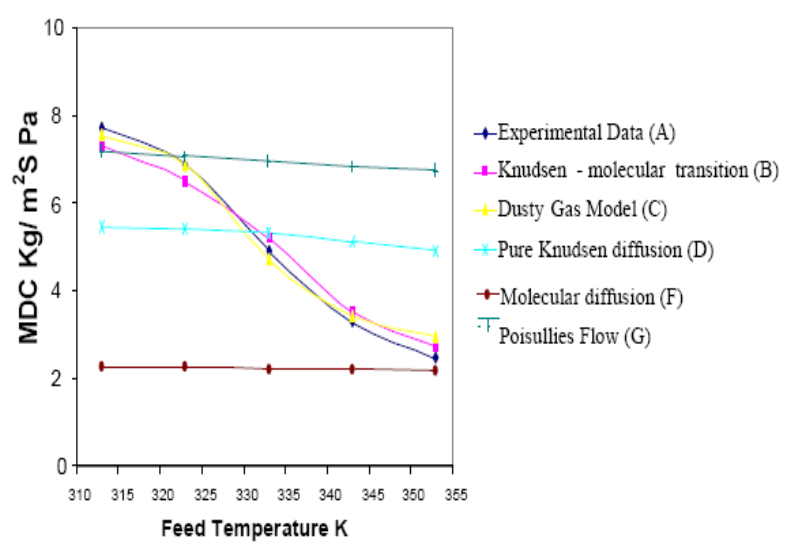

Fig. 4. MDC Vs feed temperature for orange juice.

\section{CONCLUSION}

The effects of the various parameters on permeate flux has been investigated in the DCMD configuration. The Dusty 
Gas Model describes membrane distillation through a porous membrane. Analysis of an applied Dusty Gas Model has identified a possible way to optimize flux by an optimal combination of operating parameter and design factor. A model for a membrane distillation process in a plate-and-frame unit has been developed. It is based on a mass and energy balance equation for hydrodynamic, temperature and concentration boundary layers. The model consists of an analytical equation and permits simulation or analysis of the influence of various factors to permeate flux.

\section{REFERENCES}

[1] M. S. E. Bourawi, Z. Ding, R. Ma, and M. Khayet, "A framework for better understanding membrane distillation separation process", Journal of Membrane Science, vol. 285, issues 1-2, pp. 4-29, November 2006.

[2] K. W. Lawson and D. R. Lloyd, "Review Membrane distillation", Journal of Membrane Science, vol. 124, pp. 1-25, 1997.

[3] R. W. Schofield, A. G. Fane, and C. J. D. Fell, "Heat and mass transfer in membrane distillation," Journal of Membrane Science, vol. 33, pp. 299-313, 1987

[4] F. A. Banat and J. Simandl, "Theoretical and experimental study in membrane distillation," Desalination, vol. 95, Issue 1, pp. 39-52, March 1994.

[5] S. Bandini, C. Gostoli, and G. C. Sarti, "Role of Heat and Mass Transfer in Membrane Distillation Process," Desalination, vol. 81, pp. 91-106, 1991.

[6] W. T. Hanbury and T. Hodgkiess, "Membrane Distillation - An Assessment," Desalination, vol. 56, pp. 287-297, 1985.

[7] A. S. Jonsson, R. Wimmerstedt, and A. C. Harrysson, "Membrane Distillation - A theoretical study of evaporation through microporous membrane," Desalination, vol. 56, pp. 237-249, 1985.

[8] S. Bandini, C. Gostoli, and G. C. Sarti, "Role of heat and mass transfer in membrane distillation process," Desalination, vol. 81, pp. 91-106, July 1991.

[9] G. Galaverna, G. D. Silvestro A. Cassano, S. Forza, A. Dossena, E. Drioli, and R. Marchelli, "A new integrated membrane process for the production of concentrated blood orange juice: Effect on bioactive compounds and antioxidant activity," Food Chemistry, 2007.

[10]. B.-J. Rico, S. M. Anne, V. Camilla, and J. Gunnar, "Recovery of volatile aroma compounds from black currant juice by vacuum membrane distillation," Journal of Food Engineering, vol. 64, issue 1, pp. 23-31, September 2004.

Oleksandr S. Lukanin, Sergiy M. Gunko, Mikhaylo T. Bryk, and Rinat R. Nigmatullin, "The effect of content of apple juice biopolymers on the concentration by membrane distillation," Journal of Food Engineering, vol. 60, issue 3, pp. 275-280, December 2003.

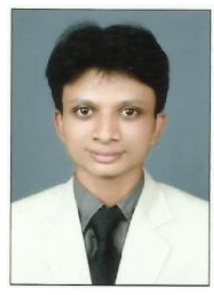

Mrunal B. Morey is from Anjangaon Surji, Dist-Amravati, Maharashtra, India. He was born on September 1, 1992. Final year Chemical Engineering, Jawaharlal Darda Institute of Engineering and Technology, Yavatmal, Maharashtra, India. He was University topper during second \&third year, and he is acquiring the position of class representative for last two years. He has done a project on Desalination Using Regenerated Waste Filters. He has presented a seminar on Forward Osmosis. He has done the industrial training in Mylan Laboratories Limited (unit-1), Kazipally Industrial area, Medak, Hyderabad, India. He has done training and plant visit in Rashtriya Chemical Fertilizers Ltd Chembur, Mumbai, India. He is interested in Unit Operations, Separation Processes.

Mr. Morey is general secretary of college for session 2013-2014. He was the Best Student of college for the session 2010-2011. He is studen organizer of National conference "GreenChem". He is a Student Representative Council (SRC) member from last two years. He has worked as a correspondence coordinator in National conference "GreenChem2013" held on 27 Feb 2013, he is coordinator of students association of Chemical Engineering (SACE) club.

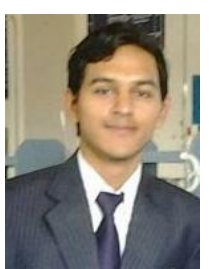

Vipul N. Gandhi is from Yavatmal, Maharashtra, India. He was born on March 20, 1993. Third year Chemica Engineering, Jawaharlal Darda Institute of Engineering and Technology, Yavatmal, Maharashtra, India. He was University topper during second year, and he is the class representative for the session 2013-2014.

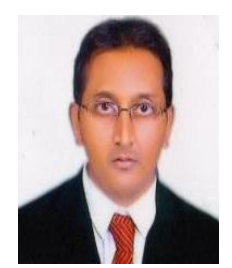

Samir K. Deshmukh was born on May 23, 1973. He is an associate professor, in the Chemical Engineering Department, Jawaharlal Darda Institute of Engineering and Technology, Yavatmal, Maharashtra, India. He has 17.8 years of total experience, 15.8 years teaching experience \& 2 years of Industrial experience in Indian Oxalate Pvt. Ltd., Lote Purshuram as shift Incharge. Currently working as an associate professor. He has research interest in Mass Transfer, Membrane Technology, Environmental Engineering, Computational Fluid Dynamics.

Dr. Deshmukh is coordinator of "Environmental awareness Movement". Convener of National conference "GreenChem2013" on 27 Feb 2013. Convener of National conference "GreenChem2012" on 27-28 Feb 2012.Organizing secretary of National Conference on Impact of Global Recession on Technical 